\title{
Effects of interleukin-1 antagonism on cortisol levels in individuals with obesity: a randomized clinical trial
}

\author{
Fahim Ebrahimi ${ }^{1,2, *}$, Sandrine A Urwyler ${ }^{1,2, *}$, Philipp Schuetz ${ }^{2,3}$, Beat Mueller ${ }^{2,3}$, Luca Bernasconi ${ }^{4}$, Peter Neyer ${ }^{4}$, \\ Marc Y Donath ${ }^{1,2}$ and Mirjam Christ-Crain ${ }^{1,2}$ \\ ${ }^{1}$ Division of Endocrinology, Diabetes and Metabolism, Department of Internal Medicine, University of Basel Hospital, Basel, Switzerland \\ ${ }^{2}$ Department of Clinical Research, University of Basel Hospital, Basel, Switzerland \\ ${ }^{3}$ Division of Endocrinology, Diabetes and Metabolism, University Department of Medicine, Kantonsspital Aarau, Aarau, Switzerland \\ ${ }^{4}$ Department of Laboratory Medicine, Kantonsspital Aarau, Aarau, Switzerland \\ Correspondence should be addressed to M Christ-Crain: mirjam.christ@usb.ch \\ *(F Ebrahimi and S A Urwyler contributed equally to this work)
}

\begin{abstract}
Background: Anti-inflammatory treatment with interleukin-1 (IL-1) antagonism decreases both cortisol and adrenocorticotropin hormone (ACTH) levels in individuals with obesity in short term. However, it remains unknown whether these effects persist upon prolonged treatment.

Methods: In this double-blind, parallel-group trial involving patients with features of the metabolic syndrome, 33 patients were randomly assigned to receive $100 \mathrm{mg}$ of anakinra (recombinant human IL-1 receptor antagonist) subcutaneously twice-daily and 34 patients to receive placebo for 4 weeks. For this analysis, change in cortisol and ACTH levels from baseline to 4 weeks were predefined end points of the trial. Results: The mean age was 54 years, baseline cortisol levels were $314 \mathrm{nmol} / \mathrm{L}$ (IQR 241-385) and C-reactive protein (CRP) levels were $3.4 \mathrm{mg} / \mathrm{L}$ (IQR 1.7-4.8). Treatment with anakinra led to a significant decrease in cortisol levels at day 1 when compared to placebo with an adjusted between-group difference of $28 \mathrm{nmol} / \mathrm{L}(95 \% \mathrm{Cl},-7$ to -43 ; $P=0.03)$. After 4 weeks, the cortisol-lowering effect of anakinra was attenuated and overall was statistically not significant $(P=0.72)$. Injection-site reactions occurred in 21 patients receiving anakinra and were associated with higher CRP and cortisol levels. Conclusions: IL-1 antagonism decreases cortisol levels in male patients with obesity and chronic low-grade inflammation on the short term. After prolonged treatment, this effect is attenuated, probably due to injection-site reactions (ClinicalTrials.gov, NCT02672592).
\end{abstract}
Key Words
- metabolic syndrome
- inflammation
- interleukin-1
- HPA axis
- anakinra

\section{Introduction}

Obesity is a pandemic, associated with high morbidity and mortality, particularly due to the onset and progression of metabolic comorbidities such as hypertension, dyslipidemia and diabetes mellitus $(1,2)$. A key pathogenic pathway in the development of metabolic complications and atherosclerosis is the release of pro-inflammatory cytokines from adipose tissue promoting a state of chronic low-grade inflammation $(3,4,5)$. It has been suggested that inflammation in turn leads to an increased activity of the hypothalamus-pituitary-adrenal (HPA) axis with excess of glucocorticoids which are known to increase the risk for metabolic complications and cardiovascular mortality (6).

Interleukin-1 $\beta$ (IL-1 $\beta$ ) is known to potently stimulate hypercortisolism $(7,8)$, since it has shown to interact 
at all levels of the HPA axis: first, on the hypothalamus due to the co-localization of IL-1 and corticotropinreleasing hormone $(\mathrm{CRH})$-producing cells $(9,10)$, second on adrenocorticotropin hormone (ACTH)-producing cells in the pituitary gland (7) and third in the adrenal glands with direct stimulatory effect on cortisol production (11).

Therapeutic interventions aimed at counteracting inflammatory activation have proven potential to improve both glycemic control (12) and prevent cardiovascular complications (13). Recently, the large randomized controlled CANTOS trial demonstrated that antagonism of the IL-1 inflammatory pathway significantly reduced major adverse cardiovascular event rates in patients with chronic low-grade inflammation (13). These highly beneficial effects of such anti-inflammatory treatment on metabolism and atherosclerosis may to some extent be explained by a reduction of cortisol excess. We recently reported that short-term IL-1 antagonism has the capacity to decrease ACTH, serum cortisol and salivary cortisol levels in individuals with obesity and features of the metabolic syndrome (14). The aim of the current randomized, placebo-controlled study was to investigate whether these effects on the HPA axis persist upon prolonged IL-1 receptor antagonism.

\section{Methods}

\section{Study design}

This is a secondary analysis of a placebo-controlled, doubleblind, randomized intervention trial which was conducted at two tertiary care centers in Switzerland involving middle-aged men with obesity and features of metabolic syndrome and moderately low levels of total testosterone. The primary aim of the study was to investigate the effects of interleukin-1 antagonism on the hypothalamuspituitary gonadal axis (15). A predefined secondary aim was to investigate the effect of a 4-week treatment on serum cortisol levels. Patients were recruited from January 2016 to June 2017 and received either twice-daily recombinant human interleukin-1-receptor antagonist $(200 \mathrm{mg}$ of anakinra (Kineret) per day) or placebo for 4 weeks. Efficacy was assessed at baseline, after 1 day, 4 weeks and 3 months. Data on adverse events were collected during the treatment period and for 2 months thereafter.

Participants received a set of study medication, which was prepared prior to the initiation of the study and packed by the Hospital Pharmacy, University Hospital Basel, which was responsible for blinding procedures and randomization.

\section{Patients}

The trial was conducted according to the declaration of Helsinki and Good Clinical Practice Guidelines. The study was approved by the Ethics Committee northwest/central Switzerland (EKNZ) prior to patient recruitment and the trial was registered on ClinicalTrials.gov (clinicaltrials.gov ID: NCT02672592).

Main eligibility criteria were men aged $18-75$ years with a BMI of more than $30 \mathrm{~kg} / \mathrm{m}^{2}$, a morning total testosterone levels below $12 \mathrm{nmol} / \mathrm{L}$ and at least one of the following additional parameters of the metabolic syndrome: hyperglycemia (glycated hemoglobin more than $5.7 \%$ or $39 \mathrm{mmol} / \mathrm{mol}$ ), hypertension (blood pressure more than $130 / 85 \mathrm{mmHg}$ or treatment for hypertension) or dyslipidemia (high-density lipoprotein (HDL) lower than $1.0 \mathrm{mmol} / \mathrm{L}$, triglycerides higher than $1.7 \mathrm{mmol} / \mathrm{L}$, low-density lipoprotein (LDL) higher than $3.4 \mathrm{mmol} / \mathrm{L}$ or lipid-lowering treatment). The trial excluded from enrollment with drug abuse, infection during the last 2 months or an immunocompromised state. Complete inclusion and exclusion criteria have been published recently (15).

\section{Study procedures}

All patients provided written informed consent. Eligible patients were randomly assigned (1:1 ratio) to receive $100 \mathrm{mg}$ of the recombinant human interleukin-1 receptor antagonist anakinra, purchased by Swedish Orphan Biovitrum, or an identically appearing placebo twice-daily, as self-administered, subcutaneous injections for 4 weeks. Compliance to treatment was assessed by counting returned empty syringes, by keeping a medication diary and by measurement of plasma interleukin-1 receptor antagonist concentrations at 4 weeks.

At a screening visit, an investigator collected medical history, performed physical examination and a blood sampling. The study procedures have been reported in detail previously (15).

\section{Laboratory measurements}

Routine clinical laboratory tests were performed locally at both participating centers. Serum samples were stored at $-80^{\circ} \mathrm{C}$. CRP was determined with an immunoturbidimetric assay (Tina-quant C-reactive Protein Gen. 3 Test, Roche Diagnostics $\mathrm{GmbH})$. ACTH was quantified with a chemiluminescence immunoassay (ACTH Immulite, Siemens Healthcare Diagnostics Products Ltd.), with a reference range $<46.0 \mathrm{pg} / \mathrm{mL}$. Serum total cortisol was

This work is licensed under a Creative Commons Attribution-NonCommercial-NoDerivatives 4.0 Internationab ticense.ifica.com at 04/26/2023 01:45:05PM 
measured using a commercially available and certified liquid chromatography tandem mass spectrometry (LC-MS/MS) assay (MassChrom Steroids; Chromsystems, Munich, Germany). The analyses were performed using an UltiMate 3000 ultra-high-performance liquid chromatography (UHPLC) system (Thermo Fisher Scientific) coupled to an AB Sciex 5500 QTRAP quadrupole mass spectrometer (AB Sciex, Darmstadt, Germany). The Turbo $V$ ion source (AB Sciex) was operated in positive electrospray ionization mode. The targeted screening method employed the multiple reaction monitoring mode of operation using two transitions for each analysis sample and two for the internal standard. Prior to injection into the UHPLC system, serum samples were subjected to a complex process of reversed phase 96-well solid-phase extraction, purification and concentration as described in the MassChrom Steroids user's manual.

According to the manufacturer's manual, the lower limit of quantitation was $4 \mathrm{nmol} / \mathrm{L}$ and linear range $4-1656 \mathrm{nmol} / \mathrm{L}$. The relative recovery was calculated by adding known amounts of cortisol to serum samples and analyzing by LC-MS/MS and amounted to $102 \pm 3 \%$. There is no measurable carryover effect on the blank after running the highest standard $(810 \mathrm{nmol} / \mathrm{L})$. The interassay coefficient of variation is $2.6 \%$ at $71 \mathrm{nmol} / \mathrm{L}$, $2.1 \%$ at $170 \mathrm{nmol} / \mathrm{L}$ and $3.6 \%$ at $494 \mathrm{nmol} / \mathrm{L}$, respectively.

\section{Statistical analysis}

Discrete variables are expressed as counts (percentage) and continuous variables as medians (interquartile range (IQR)) unless stated otherwise. Frequency comparisons were made with the chi-square test. We used a linear regression (ANCOVA) model adjusted for the baseline value of the dependent variable to investigate changes in cortisol levels and other secondary outcomes. For linear regression analyses cortisol levels were log-transformed in order to achieve normal distribution. Multivariate analyses were performed adjusting for age, BMI, CRP and occurrence of injection-site reactions. Changes within each group were tested with the use of a paired $t$-test or with Wilcoxon signed-rank test in case of nonnormal distribution. Predefined subgroup analyses were performed based on baseline CRP levels of less than or equal to or greater than $2 \mathrm{mg} / \mathrm{L}$; baseline BMI of less than or equal to or greater than $40 \mathrm{~kg} / \mathrm{m}^{2}$, baseline total testosterone levels of less than or equal to or greater than $8 \mathrm{nmol} / \mathrm{L}$, on the basis of the occurrence of injectionsite reactions or on the basis of achieving on-treatment reductions in CRP at 1 week of less than or equal to or greater than $1 \mathrm{mg} / \mathrm{L}$. All $P$ values are two-sided and all CIs are at the 95\% level. There was no adjustment for multiplicity. Statistical analyses were performed using STATA 14.2 (Stata Corp) and graphs were drawn with GraphPad Prism 7.3 (GraphPad Software).

\section{Results}

\section{Patient characteristics}

In total, 67 patients were included in the study, of whom all were male. Clinical and demographic baseline characteristics were well balanced between randomized groups (Table 1). The median age was 55 years, median BMI was $37 \mathrm{~kg} / \mathrm{m}^{2}$ (interquartile range (IQR) 34-39), and more than half of the patients were either prediabetic (19/67) or had type 2 diabetes mellitus (16/67) resulting in a median HbA1c of $5.8 \%$ (IQR 5.4-6.3). Further metabolic features were prevalent with 47 out of 67 patients suffering from hypertension and 57 patients from dyslipidemia. Morning fasting cortisol levels at baseline were $314 \mathrm{nmol} / \mathrm{L}$ (IQR 241-385) and median CRP levels were $3.4 \mathrm{mg} / \mathrm{L}$ (IQR 1.7-4.8), mirroring a state of chronic low-grade inflammation.

\section{Effects of IL-1 antagonism on the HPA axis}

In patients allocated to anakinra, cortisol levels at baseline were $329 \mathrm{nmol} / \mathrm{L}$ (IQR 267 to 382 ) and decreased by $-16 \mathrm{nmol} / \mathrm{L}$ (IQR (-87) to 77 ) after 1 day of treatment. In comparison, patients receiving placebo had a baseline level of $293 \mathrm{nmol} / \mathrm{L}$ (IQR 231-387) and a median increase by $2 \mathrm{nmol} / \mathrm{L}(\mathrm{IQR}(-51)$ to 46$)$ at day 1 . There was a mean adjusted between-group difference of $-28 \mathrm{nmol} / \mathrm{L}$ (95\% CI, $(-7)$ to $(-43) ; P=0.03$ ) (Fig. 1). However, at 4 weeks, this effect was no longer visible. Over the treatment period of 28 days, in both groups, cortisol levels increased when compared to baseline. In the anakinra group, cortisol levels increased by $18 \mathrm{nmol} / \mathrm{L}$ (IQR (-43) to 93), as compared to an increase of $31 \mathrm{nmol} / \mathrm{L}$ (IQR (-29) to 95) in the placebo group, yielding a nonsignificant between-group difference of $-18 \mathrm{nmol} / \mathrm{L}$ (95\% CI, (-71) to 36; $P=0.72$ ). At 3-month follow-up visit, there was likewise no significant difference in cortisol levels between anakinra and placebo group (betweengroup difference $20 \mathrm{nmol} / \mathrm{L} ; 95 \% \mathrm{CI}(-40)$ to $81 ; P=0.50)$. There was no effect on ACTH levels at any time point $(P>0.05)$. Likewise, over the 4 -week period there was no effect on fasting glucose levels.

This work is licensed under a Creative Commons Attribution-NonCommercial-NoDerivatives 4.0 Internationab License.ifica com at $04 / 26 / 2023$ 01:45:05PM 
Table 1 Baseline characteristics and clinical variables of enrolled patients.

\begin{tabular}{l}
\hline Characteristic/variable \\
\hline General characteristics \\
Age (years) \\
Body weight $(\mathrm{kg})$ \\
Body mass index $\left(\mathrm{kg} / \mathrm{m}^{2}\right)$ \\
$\quad<35$ \\
$35-40$ \\
$>40$ \\
Waist circumference $(\mathrm{cm})$ \\
Body surface area $\left(\mathrm{m}^{2}\right)$ \\
Systolic blood pressure $(\mathrm{mmHg})$ \\
Diastolic blood pressure $(\mathrm{mmHg})$ \\
Gynaecomastia \\
Comorbidities \\
Prediabetes \\
Diabetes mellitus \\
Diet \\
Oral drug \\
Insulin (alone or with oral drug) \\
Hypertension \\
Use of antihypertensive medication \\
Dyslipidemia \\
Statin treatment \\
Obstructive sleep apnea \\
CPAP treatment \\
Smoking status \\
Former \\
Current \\
Packyears \\
Psychiatric disease \\
Laboratory values \\
HbA1c (\%) \\
Fasting glucose (mmol/L) \\
Total cholesterol (mmol/L) \\
LDL cholesterol (mmol/L) \\
HDL cholesterol (mmol/L) \\
Triglycerides (mmol/L) \\
Cortisol (nmol/L) \\
Adrenocorticotrope hormone (pg/mL) \\
C-reactive protein (mg/L) \\
Interleukin-6 (pg/mL) \\
\hline
\end{tabular}

\begin{tabular}{c}
\hline Total $(n=67)$ \\
\hline $55(44-65)$ \\
$113(104-124)$ \\
$37(34-39)$ \\
$21 / 67$ \\
$35 / 67$ \\
$11 / 67$ \\
$123(117-132)$ \\
$2.4(2.2-2.5)$ \\
$133(126-142)$ \\
$89(80-93)$ \\
$36 / 67$ \\
$19 / 67$ \\
$16 / 67$ \\
$1 / 16$ \\
$14 / 16$ \\
$1 / 16$ \\
$47 / 67$ \\
$30 / 47$ \\
$57 / 67$ \\
$18 / 57$ \\
$21 / 67$ \\
$14 / 21$ \\
$26 / 67$ \\
$16 / 67$ \\
$20(10-30)$ \\
$7 / 67$ \\
$5.8(5.4-6.3)$ \\
$5.6(5.1-6.7)$ \\
$4.8(3.8-5.7)$ \\
$2.9(2.1-3.8)$ \\
$1.1(1.0-1.3)$ \\
$1.7(1.3-2.6)$ \\
$314(241-385)$ \\
$3.4(1.7-4.8)$ \\
$2.3(2.0-3.7)$ \\
\hline \\
\\
\end{tabular}

\begin{tabular}{|c|}
\hline Placebo $(n=34)$ \\
\hline $55(43-65)$ \\
\hline $114(102-124)$ \\
\hline $36(34-40)$ \\
\hline $11 / 34$ \\
\hline $18 / 34$ \\
\hline $5 / 34$ \\
\hline $123(116-134)$ \\
\hline $2.4(2.2-2.5)$ \\
\hline 132 (123-139) \\
\hline 85 (78-94) \\
\hline $17 / 34$ \\
\hline $9 / 34$ \\
\hline $7 / 34$ \\
\hline $0 / 7$ \\
\hline $6 / 7$ \\
\hline $1 / 7$ \\
\hline $21 / 34$ \\
\hline $14 / 21$ \\
\hline $29 / 34$ \\
\hline $7 / 29$ \\
\hline $7 / 34$ \\
\hline $5 / 7$ \\
\hline $14 / 34$ \\
\hline $5 / 34$ \\
\hline $20(10-30)$ \\
\hline $3 / 34$ \\
\hline $5.8(5.4-6.1)$ \\
\hline $5.5(5.1-6.2)$ \\
\hline $4.7(4.0-5.5)$ \\
\hline $2.8(2.1-3.8)$ \\
\hline $1.1(1.0-1.3)$ \\
\hline $1.8(1.2-2.6)$ \\
\hline 293 (231-387) \\
\hline $23(16-33)$ \\
\hline $3.6(1.6-4.9)$ \\
\hline $2.2(2.0-3.9)$ \\
\hline
\end{tabular}

\begin{tabular}{c}
\hline Anakinra $(n=33)$ \\
\hline $55(45-67)$ \\
$113(107-122)$ \\
$37(34-39)$ \\
$10 / 33$ \\
$17 / 33$ \\
$6 / 33$ \\
$124(119-131)$ \\
$2.3(2.2-2.5)$ \\
$136(130-147)$ \\
$90(84-93)$ \\
$19 / 33$ \\
$10 / 33$ \\
$9 / 33$ \\
$1 / 9$ \\
$8 / 9$ \\
$0 / 9$ \\
$26 / 33$ \\
$16 / 26$ \\
$28 / 33$ \\
$11 / 28$ \\
$14 / 33$ \\
$9 / 14$ \\
$12 / 33$ \\
$11 / 33$ \\
$20(10-36)$ \\
$4 / 33$ \\
\end{tabular}

Data are presented as median (IQR) or fractions n/total. The body mass index is the weight in kilograms divided by the square of the height in meters. Gynaecomastia was not confirmed by ultrasonography and thus not differentiated from pseudogynaecomastia.

\section{Changes in cortisol among predefined subgroups}

When the patients were stratified into two predefined groups according to baseline inflammatory state (CRP $\geq 2 \mathrm{mg} / \mathrm{L}$ versus $<2 \mathrm{mg} / \mathrm{L})$, there was no significant between-group difference at any time point $(P>0.05)$. The proportions of individuals achieving on-treatment CRP reductions of more than $1 \mathrm{mg} / \mathrm{L}$ at 1 week were three out of 34 (9\%) in the placebo group and 25 out of $33(76 \%)$ in the anakinra group. Compared with placebo, participants allocated to anakinra who had CRP concentrations of more than $1 \mathrm{mg} / \mathrm{L}$ tended to having more pronounced reductions in cortisol levels of $-24 \mathrm{nmol} / \mathrm{L}(95 \% \mathrm{CI},(-184)$ to $136 ; P=0.77)$, although the difference did not attain statistical significance. A decrease in the change of CRP tended to correlate with a decrease in cortisol levels (day $1: R^{2}=0.198, P=0.077$ ) (Supplementary Fig. 1, see section on supplementary data given at the end of this article). Patients with a BMI at baseline of equal to or greater than $40 \mathrm{~kg} / \mathrm{m}^{2}$ tended to having a more pronounced reduction in cortisol levels by $-68 \mathrm{nmol} / \mathrm{L}(95 \% \mathrm{CI},(-197)$ to 59$)$ compared to patients with BMI below $40 \mathrm{~kg} / \mathrm{m}^{2}$. However, there was no statistical significance between the groups $(P=0.29)$. https://ec.bioscientifica.com https://doi.org/10.1530/EC-19-0201 (c) 2019 The authors Published by Bioscientifica Ltd
This work is licensed under a Creative Commons Attribution-NonCommercial-NoDerivatives 4.0 Internationab sicense.ifica . com at 04/26/2023 01:45:05PM 


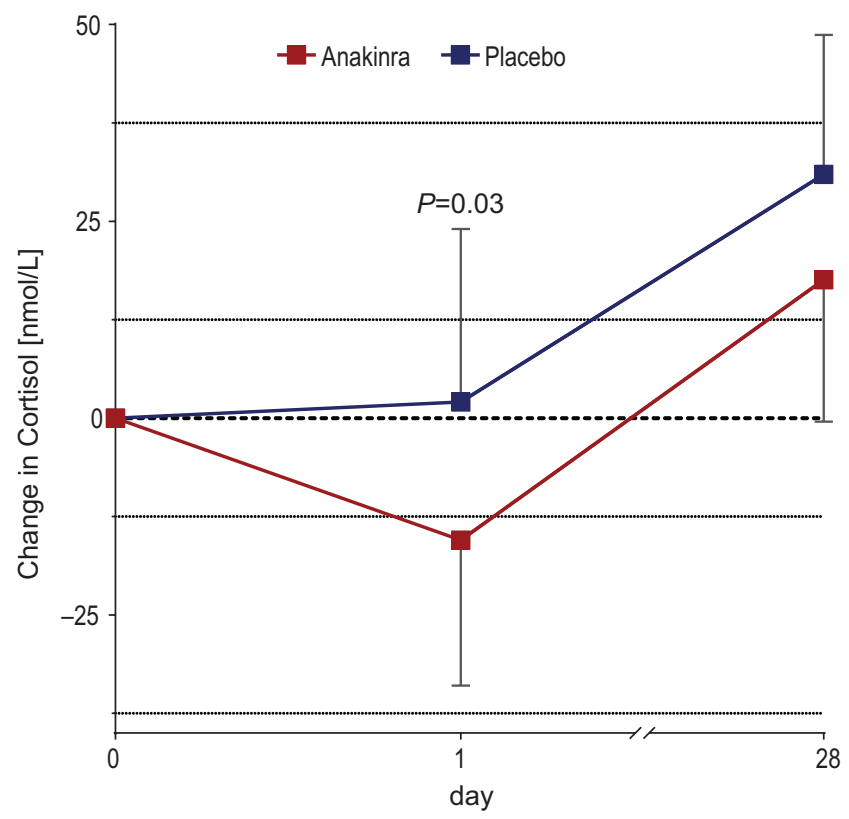

Figure 1

Effects of anakinra on serum cortisol levels. Median absolute differences in cortisol levels between the baseline value and measurements at day 1 and at end of the 4-week study period. The error bars indicate standard errors.

Though men with baseline total testosterone levels higher than $8 \mathrm{nmol} / \mathrm{L}$ tended to having a more pronounced shortterm decrease in cortisol levels upon anakinra treatment (between-group difference $-63 \mathrm{nmol} / \mathrm{L} ; 95 \% \mathrm{CI}(-125)$ to $(-0.02) ; P=0.047)$. However, similar to the total cohort the observed effect on cortisol was no longer evident at 4 weeks (between-group difference $-22 \mathrm{nmol} / \mathrm{L} ; 95 \% \mathrm{CI}$ $(-137)$ to $93 ; P=0.71)$. Baseline testosterone levels were not correlated with changes in cortisol (day $1: R^{2}=0.048$, $P=0.22 ; 4$ weeks: $R^{2}=0.033, P=0.31$ ).

During the quite short study period, there were no cardiovascular adverse events. In 21 out of 33 patients receiving anakinra developed injection-site reactions, compared to no skin reactions in the placebo group $(P<0.001)$. In the anakinra group, patients who developed injection-site reactions had higher CRP levels at 4 weeks by $0.9 \mathrm{mg} / \mathrm{L}(95 \%$ CI $(-2.8)$ to 4.7$)$ compared to patients receiving anakinra but not developing skin reactions. However, these changes between the groups did not attain statistical significance and therefore are exploratory (Fig. 2A). Similarly, at 4 weeks, cortisol levels tended to be higher by $35 \mathrm{nmol} / \mathrm{L}$ (95\% CI -43 to 113 ) in patients suffering from injection-site reactions compared to those with no skin reactions; however, changes did not meet statistical significance and are exploratory (Fig. 2B).
A

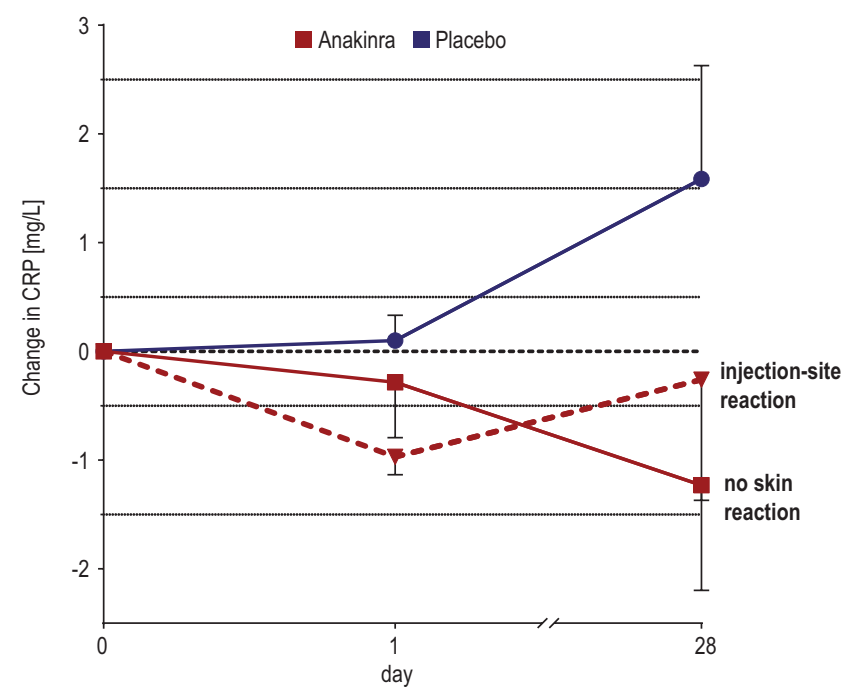

B

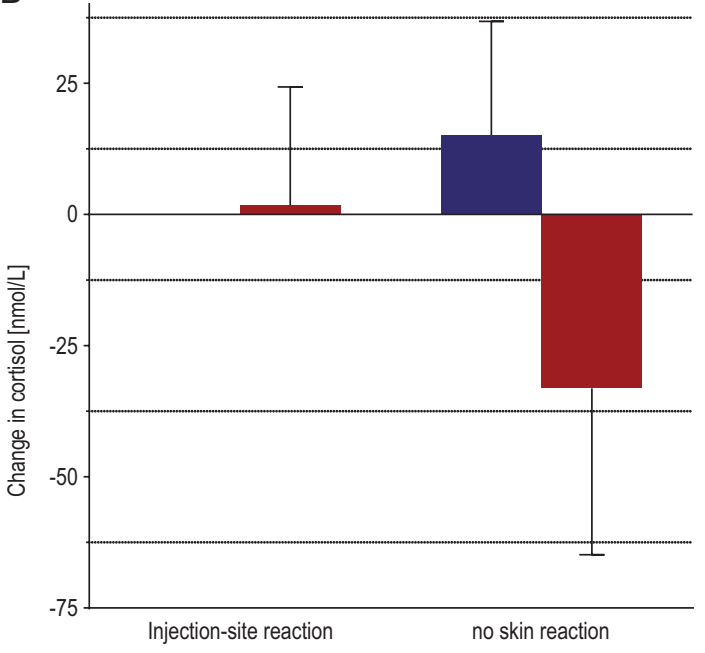

Figure 2

Injection-site reactions and cortisol levels. Panel A shows the average absolute differences in C-reactive protein levels between the baseline value and measurements at day 1 and 28 during the 4-week study period. Panel B shows the average absolute difference in cortisol levels at day 1 in each study group stratified by occurrence of injection-site reactions. Injection-site reactions emerged in 21 out of 33 patients receiving anakinra, compared to no patients in the placebo group. These analyses are exploratory, showing distinct trends, although the difference did not attain statistical significance.

\section{Discussion}

This randomized, double-blind placebo-controlled trial of IL-1 antagonism affirmed that anti-inflammatory treatment with anakinra leads to a reduction in cortisol levels in individuals with obesity and features of the metabolic syndrome on the short term, however, with no significant effect after prolonged treatment. 
Increased levels of cortisol have been associated with excess morbidity and mortality in the metabolic syndrome. Hypercortisolemia as seen in Cushing's syndrome has been known to be associated with metabolic dysregulation, development of diabetes mellitus and massive increase in cardiovascular risk profiles $(16,17)$.

Recently, the large Canakinumab Anti-Inflammatory Thrombosis Outcomes Study (CANTOS) which enrolled more than 10,000 patients with low-grade chronic inflammation, showed significantly reduced major adverse cardiovascular event rates, when targeting the interleukin-1 $\beta$ inflammatory pathway (13). However, the underlying mechanisms leading to the outcome benefit for cardiovascular events as well as all-cause mortality are still matter of debate. In the current trial, we did not observe the effects of anakinra on lipid levels when compared with placebo (15). This finding is in accordance with data from the CANTOS trial which showed that incidence of recurrent cardiovascular events was significantly reduced upon IL-1 inhibition, without any effects on LDL, HDL and triglyceride levels, respectively (13). This has led to the assumption that significant improvements in metabolism may have directly contributed to the reduced mortality aside from direct protective effects on vascular endothelium $(18,19,20,21)$. Furthermore, in our trial, patients allocated to anakinra tended to have a blood pressure-lowering effect on both systolic and diastolic blood pressure, by $-3.1 \mathrm{mmHg}$ and $-2.7 \mathrm{mmHg}$, respectively. Heart rate was not affected (15).

IL-1 antagonism has been shown to improve glycemia via improved beta-cell secretory function (12) in patients with obesity and metabolic syndrome. However, the current trial was not designed and not powered to investigate the effects on glucose metabolism, since most of the included patients did not have impaired glucose tolerance (only 16 (24\%) patients were diabetic, hence already at baseline $\mathrm{HbA1c}$ levels were rather low with a median of $5.8 \%$ (interquartile range (IQR) 5.4, 6.3)) (Table 1).

These beneficial effects on metabolism have been related to be at least in part due to a reduction in cortisol levels (14). In fact, short-term treatment with anakinra significantly decreased both serum and salivary cortisol levels which was accompanied by significant reduction in ACTH levels, providing a possible additional mechanism for the reduction in cardiovascular risk. In the current randomized controlled trial, we show that this effect on cortisol levels is primarily short term without a significant difference compared to placebo after 4 weeks.

However, circulating levels of cortisol may not fully reflect metabolic effects of IL-1 antagonism, since intracellular determinants of cortisol metabolism and action need as well to be taken into consideration. In this context, regulation of the local expression of $11 \beta$-hydroxysteroid dehydrogenase type 1 (11ß-HSD1) in adipose tissue appears to be a major factor. Adipose $11 \beta-H S D 1$ is the key enzyme catalyzing the conversion of inactive cortisone into the hormonally active cortisol $(22,23)$. In fact, previous studies have shown that individuals with obesity and metabolic syndrome have an overexpression of $11 \beta$-HSD1 in adipocytes resulting in increased conversion of cortisone to cortisol and consequently in excessive tissue-specific glucocorticoid activity (24). In fact, locally acting adipocyte-derived IL-1 $\beta$ has been shown to be one major factor stimulating the transcriptional activity and overexpression of the $11 \beta$-HSD1 gene $(25,26)$. Against this background, beneficial effects of IL-1-antagonism on insulin resistance and glucose metabolism may therefore not fully be explained by an inhibition of HPA axis and consequent reduction of circulating levels of cortisol. It is worth investigating whether the beneficial metabolic effects may at least to some be explained through downregulation of the transcriptional activity of $11 \beta-H S D 1$ within adipose tissue and thereby reduced tissue-specific concentrations of glucocorticoids.

Compared to previous studies using anakinra in cardiovascular diseases (27), higher doses were used in our trial, based on previous clinical data indicating reduced efficacy of anakinra with higher body surface area in obese patients (12). Although pro-inflammatory states have been associated with higher circulating levels of IL-1 receptor antagonist (28), this is rather counterregulatory and does not mirror a pro-inflammatory action. For this reason, we do not assume that the higher dose used in our study may have limited the efficacy of anakinra. Though, a possible explanation for the less pronounced effects on circulating levels of cortisol at 4 weeks are injection-site reactions which were relatively frequent in our study, presumably due to the higher dose of anakinra. This observation is consistent with previous studies indicating a dose-escalating incidence and severity of injection-site reactions $(29,30)$. We found diminished effects on cortisol levels in patients who developed skin reactions; this phenomenon has been described as well in earlier studies with anakinra (31) and may be due to an inflammatory reaction in the subcutaneous tissue (29). Another possible explanation of the effect attenuation with prolonged anti-inflammatory treatment might be a counterregulatory stimulatory effect of other cytokines on the HPA axis. Interleukin-6, tumor-necrosis

is work is licensed under a Creative Commons Attribution-NonCommercial-NoDerivatives 4.0 Internationab kicense.ifica, com at $04 / 26 / 2023$ 01:45:05PM 
factor- $\alpha$ (TNF- $\alpha$ ) and IL-10 derive from the visceral adipose tissue or are produced in the hypothalamus and are known to stimulate the HPA axis. Possibly, as a mechanism of compensation after the long-term blocking effects of IL-1, the stimulation via these alternative pathways might flare up and result in an re-upregulation of the HPA-activity reflected by the re-increase in cortisol levels $(32,33,34,35)$.

The following limitations need to be considered. First, inclusion of patients with only marginal systemic inflammation may have underestimated the overall effects of IL-1 antagonism on metabolism. Second, this is a secondary analysis and the original study was not powered to find a difference in cortisol levels. Third, the TestIL study was only performed in Caucasian men at two sites in Switzerland, so it is unclear whether these results can be extrapolated to individuals from other races, sex or countries. However, strengths of our study include the randomized, controlled and double-blind design, the high accuracy and reproducibility of the measurement methods, and correlation of laboratory effects with clinical variables.

In conclusion, these data contribute to the understanding of the interplay between obesity, increased activity in the HPA axis, and development of metabolic complications. However, larger and longer term studies with anti-inflammatory therapy are warranted to analyze additional mediators in this relationship and to further examine the hypothesis that beneficial effects of IL-1 antagonism on metabolism and cardiovascular outcome may at least to some extent be explained by a reduced activity of HPA axis and diminished tissue-specific cortisol action.

\section{Supplementary data}

This is linked to the online version of the paper at https://doi.org/10.1530/ EC-19-0201.

\section{Declaration of interest}

M D is listed as the inventor on a patent filed in 2003 for the use of an interleukin-1-receptor antagonist for the treatment of or prophylaxis against type 2 diabetes. The other authors have nothing to disclose.

\section{Funding}

M C C received a grant of the Swiss National Foundation (Nr PP00P3-12346), F E was supported by the 'Wissenschaftspool' of the University Hospital Basel, a grant of the University of Basel (Nachwuchsfoerderung 2017), and through the 'Young Talents in Clinical Research' program by the Bangerter Foundation and the Swiss Academy of Medical Sciences (SAMS). The funding sources were neither involved in the design of the study nor in the writing of the manuscript.

\section{Acknowledgments}

The authors gratefully thank Nina Hutter and Cemile Bathelt for excellent assistance at study visits and Christoph Saxer for technical assistance for laboratory analyses.

\section{References}

1 World Health Organization. Fact sheet: Obesity and overweight. Geneva, Switzerland: WHO, 2018. (available at: http://www.who.int/ news-room/fact-sheets/detail/obesity-and-overweight)

2 Flegal KM, Graubard BI, Williamson DF \& Gail MH. Cause-specific excess deaths associated with underweight, overweight, and obesity. JAMA 2007298 2028-2037. (https://doi.org/10.1001/ jama.298.17.2028

3 Ridker PM, Wilson PWF \& Grundy SM. Should C-reactive protein be added to metabolic syndrome and to assessment of global cardiovascular risk? Circulation 2004109 2818-2825. (https://doi. org/10.1161/01.CIR.0000132467.45278.59)

4 Donath MY, Dalmas É, Sauter NS \& Boni-Schnetzler M. Inflammation in obesity and diabetes: islet dysfunction and therapeutic opportunity. Cell Metabolism 201317 860-872. (https://doi. org/10.1016/j.cmet.2013.05.001)

5 Cottam DR, Mattar SG, Barinas-Mitchell E, Eid G, Kuller L, Kelley DE \& Schauer PR. The chronic inflammatory hypothesis for the morbidity associated with morbid obesity: implications and effects of weight loss. Obesity Surgery 200414 589-600. (https://doi. org/10.1381/096089204323093345)

6 Anagnostis P, Athyros VG, Tziomalos K, Karagiannis A \& Mikhailidis DP. Clinical review: the pathogenetic role of cortisol in the metabolic syndrome: a hypothesis. Journal of Clinical Endocrinology and Metabolism 200994 2692-2701. (https://doi. org/10.1210/jc.2009-0370)

7 Bernton EW, Beach JE, Holaday JW, Smallridge RC \& Fein HG. Release of multiple hormones by a direct action of interleukin-1 on pituitary cells. Science 1987238 519-521. (https://doi.org/10.1126/ science.2821620)

8 Turnbull AV \& Rivier CL. Regulation of the hypothalamic-pituitaryadrenal axis by cytokines: actions and mechanisms of action. Physiological Reviews 199979 1-71. (https://doi.org/10.1152/ physrev.1999.79.1.1)

9 Woloski BM, Smith EM, Meyer WJ, Fuller GM \& Blalock JE. Corticotropin-releasing activity of monokines. Science 1985230 1035-1037. (https://doi.org/10.1126/science.2997929)

10 Navarra P, Tsagarakis S, Faria MS, Rees LH, Besser GM \& Grossman AB. Interleukins-1 and -6 stimulate the release of corticotropin-releasing hormone-41 from rat hypothalamus in vitro via the eicosanoid cyclooxygenase pathway. Endocrinology 1991128 37-44. (https://doi.org/10.1210/endo-128-1-37)

11 Besedovsky HO \& del Rey A. Immune-neuro-endocrine interactions: facts and hypotheses. Endocrine Reviews 199617 64-102. (https://doi. org/10.1210/edrv-17-1-64)

12 Larsen CM, Faulenbach M, Vaag A, Volund A, Ehses JA, Seifert B, Mandrup-Poulsen T \& Donath MY. Interleukin-1-receptor antagonist in type 2 diabetes mellitus. New England Journal of Medicine 2007356 1517-1526. (https://doi.org/10.1056/NEJMoa065213)

13 Ridker PM, Everett BM, Thuren T, MacFadyen JG, Chang WH, Ballantyne C, Fonseca F, Nicolau J, Koenig W, Anker SD, et al. Antiinflammatory therapy with canakinumab for atherosclerotic disease. New England Journal of Medicine 2017377 1119-1131. (https://doi.org/10.1056/NEJMoa1707914)

14 Urwyler SA, Schuetz P, Ebrahimi F, Donath MY \& Christ-Crain M. Interleukin-1 antagonism decreases cortisol levels in obese individuals. Journal of Clinical Endocrinology and Metabolism 2017102 1712-1718. (https://doi.org/10.1210/jc.2016-3931) 
15 Ebrahimi F, Urwyler SA, Straumann S, Doerpfeld S, Bernasconi L, Neyer P, Schuetz P, Mueller B, Donath MY \& Christ-Crain M. IL-1 antagonism in men with metabolic syndrome and low testosterone: a randomized clinical trial. Journal of Clinical Endocrinology and Metabolism 2018103 3466-3476. (https://doi.org/10.1210/jc.2018-00739)

16 Clayton RN, Jones PW, Reulen RC, Stewart PM, Hassan-Smith ZK, Ntali G, Karavitaki N, Dekkers OM, Pereira AM, Bolland M, et al. Mortality in patients with Cushing's disease more than 10 years after remission: a multicentre, multinational, retrospective cohort study. Lancet: Diabetes and Endocrinology 20164 569-576. (https://doi. org/10.1016/S2213-8587(16)30005-5)

17 Neary NM, Booker OJ, Abel BS, Matta JR, Muldoon N, Sinaii N, Pettigrew RI, Nieman LK \& Gharib AM. Hypercortisolism is associated with increased coronary arterial atherosclerosis: analysis of noninvasive coronary angiography using multidetector computerized tomography. Journal of Clinical Endocrinology and Metabolism 201398 2045-2052. (https://doi.org/10.1210/jc.2012-3754)

18 Shimokawa H, Ito A, Fukumoto Y, Kadokami T, Nakaike R, Sakata M, Takayanagi T, Egashira K \& Takeshita A. Chronic treatment with interleukin-1 beta induces coronary intimal lesions and vasospastic responses in pigs in vivo. The role of platelet-derived growth factor. Journal of Clinical Investigation 199697 769-776. (https://doi. org/10.1172/JCI118476)

19 Duewell P, Kono H, Rayner KJ, Sirois CM, Vladimer G, Bauernfeind FG, Abela GS, Franchi L, Nuñez G, Schnurr M, et al. NLRP3 inflammasomes are required for atherogenesis and activated by cholesterol crystals. Nature 2010464 1357-1361. (https://doi. $\operatorname{org} / 10.1038 /$ nature08938)

20 Dinarello CA. Interleukin-1 in the pathogenesis and treatment of inflammatory diseases. Blood 2011117 3720-3732. (https://doi. org/10.1182/blood-2010-07-273417)

21 Xiao H, Lu M, Lin TY, Chen Z, Chen G, Wang WC, Marin T, Shentu TP, Wen L, Gongol B, et al. Sterol regulatory element binding protein 2 activation of NLRP3 inflammasome in endothelium mediates hemodynamic-induced atherosclerosis susceptibility. Circulation 2013128 632-642. (https://doi.org/10.1161/ CIRCULATIONAHA.113.002714)

22 Espíndola-Antunes D \& Kater CE. Adipose tissue expression of 11betahydroxysteroid dehydrogenase type 1 in Cushing's syndrome and in obesity. Arquivos Brasileiros de Endocrinologia e Metabologia 200751 1397-1403. (https://doi.org/10.1590/S0004-27302007000800027)

23 Stewart PM \& Krozowski ZS. 11beta-Hydroxysteroid dehydrogenase. Vitamins and Hormones 199957 249-324.

24 Tomlinson JW, Walker EA, Bujalska IJ, Draper N, Lavery GG, Cooper MS, Hewison M \& Stewart PM. 11Beta-hydroxysteroid dehydrogenase type 1: a tissue-specific regulator of glucocorticoid response. Endocrine Reviews 200425 831-866. (https://doi. org/10.1210/er.2003-0031)

25 Tomlinson JW, Moore J, Cooper MS, Bujalska I, Shahmanesh M, Burt C, Strain A, Hewison M \& Stewart PM. Regulation of expression of 11beta-hydroxysteroid dehydrogenase type 1 in adipose tissue: tissue-specific induction by cytokines. Endocrinology 2001142 1982-1989. (https://doi.org/10.1210/endo.142.5.8168)

26 Wake DJ, Rask E, Livingstone DEW, Söderberg S, Olsson T \& Walker BR. Local and systemic impact of transcriptional up-regulation of 11beta-hydroxysteroid dehydrogenase type 1 in adipose tissue in human obesity. Journal of Clinical Endocrinology and Metabolism 200388 3983-3988. (https://doi.org/10.1210/ jc.2003-030286)

27 van Tassell BW, Toldo S, Mezzaroma E \& Abbate A. Targeting interleukin-1 in heart disease. Circulation 2013128 1910-1923. (https://doi.org/10.1161/CIRCULATIONAHA.113.003199)

28 Dinarello CA, Simon A \& van der Meer JWM. Treating inflammation by blocking interleukin-1 in a broad spectrum of diseases. Nature Reviews: Drug Discovery 201211 633-652. (https://doi.org/10.1038/ nrd3800)

29 Kaiser C, Knight A, Nordström D, Pettersson T, Fransson J, Florin-Robertsson E \& Pilström B. Injection-site reactions upon Kineret (anakinra) administration: experiences and explanations. Rheumatology International 201232 295-299. (https://doi. org/10.1007/s00296-011-2096-3)

30 Cohen S, Hurd E, Cush J, Schiff M, Weinblatt ME, Moreland LW, Kremer J, Bear MB, Rich WJ \& McCabe D. Treatment of rheumatoid arthritis with anakinra, a recombinant human interleukin-1 receptor antagonist, in combination with methotrexate: results of a twenty-four-week, multicenter, randomized, double-blind, placebocontrolled trial. Arthritis and Rheumatism 200246 614-624. (https:// doi.org/10.1002/art.10141)

31 van Asseldonk EJP, Stienstra R, Koenen TB, Joosten LAB, Netea MG \& Tack CJ. Treatment with anakinra improves disposition index but not insulin sensitivity in nondiabetic subjects with the metabolic syndrome: a randomized, double-blind, placebo-controlled study. Journal of Clinical Endocrinology and Metabolism 201196 2119-2126. (https://doi.org/10.1210/jc.2010-2992)

32 van der Meer MJ, Sweep CG, Rijnkels CE, Pesman GJ, Tilders FJ, Kloppenborg PW \& Hermus AR. Acute stimulation of the hypothalamic-pituitary-adrenal axis by IL-1 beta, TNF alpha and IL-6: a dose response study. Journal of Endocrinological Investigation 199619 175-182. (https://doi.org/10.1007/BF03349862)

33 Smith EM, Cadet P, Stefano GB, Opp MR \& Hughes TK. IL-10 as a mediator in the HPA axis and brain. Journal of Neuroimmunology 1999 100 140-148. (https://doi.org/10.1016/S0165-5728(99)00206-4)

34 Sharp BM, Matta SG, Peterson PK, Newton R, Chao C \& Mcallen K. Tumor necrosis factor-alpha is a potent ACTH secretagogue: comparison to interleukin-1 beta. Endocrinology 1989124 3131-3133. (https://doi.org/10.1210/endo-124-6-3131)

35 Weber MM, Michl P, Auernhammer CJ \& Engelhardt D. Interleukin-3 and interleukin- 6 stimulate cortisol secretion from adult human adrenocortical cells. Endocrinology 1997138 2207-2210. (https://doi. org/10.1210/endo.138.5.5239)

Received in final form 18 April 2019

Accepted 1 May 2019

Accepted Preprint published online 1 May 2019 https://ec.bioscientifica.com https://doi.org/10.1530/EC-19-0201
(C) 2019 The authors Published by Bioscientifica Ltd

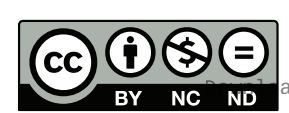

This work is licensed under a Creative Commons Attribution-NonCommercial-NoDerivatives 4.0 denternationab bicense.ifica com at 04/26/2023 01:45:05PM 